\title{
Os recursos de expressão da oralidade no gênero discursivo tiras
}

\section{The resources of orality expression in the comic strips discursive genre}

\author{
Marlúcia Maria Alves ${ }^{1}$ \\ Gilberto Antônio Peres 2 \\ Mara Rúbia Fernandes ${ }^{3}$
}

DOI: $10.28998 / 2317-9945.2020 n 64 p 59-75$

\begin{abstract}
Resumo
O presente artigo discute, inicialmente, acerca do trabalho envolvendo atividades com oralidade no espaço escolar, fundamentando nossa reflexão em documentos oficiais como os Parâmetros Curriculares Nacionais (1998) e em teóricos como Marcuschi (2010); Fávero, Andrade e Aquino (2014); e Galembeck (1999). A partir dessa reflexão, pretendemos analisar os recursos de expressão da oralidade no gênero discursivo tiras, conforme Ramos (2016) e Eguti (2001). Tendo em vista tais estudos, apresentaremos sugestôes de atividades com o intuito de serem aplicadas em aulas de Lingua Portuguesa nos anos finais do Ensino Fundamental.
\end{abstract}

Palavras-chave: Oralidade. Ensino de língua portuguesa. Gênero discursivo tiras

\begin{abstract}
This paper initially discusses the work with orality activities at school, substantiated by official documents such as the Parâmetros Curriculares Nacionais (1998) and theoretical ones such as Marcuschi (2010); Fávero, Andrade and Aquino (2014); Galembeck (1999). Based on this reflection, we aim to analyze the resources of orality expression in the comic strips discursive genre, according to Ramos (2016) and Eguti (2001). In view of such studies, we will present suggestions of activities that could be done in Portuguese language classes of the final years of elementary school.
\end{abstract}

Keywords: Orality. Portuguese language teaching. Comic strips discursive genre

Recebido em: 11/03/2018.

Aceito em: 26/08/2018.

\footnotetext{
${ }^{1}$ Graduada em Letras - Língua Portuguesa e Francesa pela Universidade Federal de Minas Gerais. Mestrado em Estudos Linguísticos pela Universidade Federal de Minas Gerais (1999) e doutorado em Linguística pela mesma instituição (2008).

2 Mestre pelo Programa de Pós-Graduação Mestrado Profissional em Letras da Universidade Federal de Uberlândia. Possui graduação em Letras Português/Inglês pela Faculdade de Filosofia, Ciências e Letras de Patrocínio - atual UNICERP.

3 Mestra pelo Programa de Pós-Graduação Mestrado Profissional em Letras da Universidade Federal de Uberlândia e graduada em Letras - Português pela mesma instituição (1998). Atualmente é Professora de Língua Portuguesa da Prefeitura Municipal de Uberlândia.
} 


\section{Introdução}

$\mathrm{Na}$ contemporaneidade, uma sociedade que não possui um código escrito para se comunicar é considerada atrasada e obsoleta. Esse é um pensamento respaldado, entre outros, por conhecimentos europeus surgidos a partir do século XVII, que colocavam as culturas conhecedoras de sistemas de escrita do tipo alfabético no patamar mais alto de um continuum conceitual: ausência de escrita/escrita não alfabética/escrita alfabética, de acordo com Gnerre (1998). Talvez seja, em parte, por isso que o texto escrito é tão valorizado nos domínios sociais ${ }^{4}$ escolares, assim como em tantos outros que o priorizam.

Entretanto, sabemos que a língua, mesmo a materna, deve ser trabalhada no ambiente escolar em todas as suas dimensões: fala, escrita, escuta e leitura, não somente na dimensão da escrita. Sabemos também que, há duas décadas, os Parâmetros Curriculares Nacionais (doravante PCN) já chamam a atenção para o trabalho com a oralidade nas salas de aula do Ensino Fundamental (doravante EF), que é um dos quatro eixos temáticos ${ }^{5}$ sugeridos por esses documentos oficiais. Segundo esses documentos, é papel da escola ensinar o aluno a "posicionar-se de maneira crítica, responsável e construtiva nas diferentes situações sociais, utilizando o diálogo como forma de mediar conflitos e de tomar decisões coletivas" (BRASIL, 1998, p. 7, grifo nosso).

No entanto, no ambiente escolar, não ocorre um planejamento relevante para que a oralidade seja trabalhada de maneira mais contundente. De acordo com os PCN,

acreditando que a aprendizagem da língua oral, por se dar no espaço doméstico, não é tarefa da escola, as situações de ensino vêm utilizando a modalidade oral da linguagem unicamente como instrumento para permitir o tratamento dos diversos conteúdos (BRASIL, 1998, p. 24).

Podemos constatar que a oralidade é ainda menosprezada na maioria das aulas do Ensino Fundamental. Os PCN (BRASIL, 1998, p. 54) recomendam o trabalho com gêneros escritos e orais, citando vinte gêneros orais e trinta escritos, porém não fornecem subsídios teóricos ao professor para fazer esse trabalho. Felizmente, na atualidade brasileira, já contamos com consideráveis publicações sobre esse tema e, com esse respaldo teórico, é possível desenvolver excelentes estratégias didáticas para a realização de um bom trabalho com oralidade nas salas de aula do EF. Os livros didáticos de Língua Portuguesa (doravante LP) nem sempre trazem atividades consistentes sobre a oralidade, entretanto, ressaltamos que eles não devem ser os únicos instrumentos didáticos utilizados pelos professores, tampouco o trabalho com a oralidade é tarefa exclusiva dos professores de LP.

Para Marcuschi (2010), é necessário avaliar o grau de consciência linguística dos estudantes e o seu domínio da noção das relações entre o texto oral e o escrito. Portanto, a escrita deve ser entendida como uma modalidade de uso da língua complementar à oralidade, visto que fala e escrita não são polares nem dicotômicas; cada uma tem suas especificidades, que devem ser consideradas. Há eventos de oralidade mais ou menos formais, tanto quanto os eventos de letramento. Isso reforça, mais uma vez, a importância de uma dedicação maior aos eventos de oralidade em sala de aula, uma vez que é a escola o lugar onde as crianças têm a oportunidade de adquirir conhecimentos a respeito de como organizar e/ou planejar suas participações em conversas, debates, entre outros tantos

\footnotetext{
4 O conceito de domínios sociais adotado neste artigo está pautado pelas considerações de Marcuschi (2008).

${ }^{5}$ Os quatro eixos temáticos propostos pelos PCN são: leitura de textos, produção de textos escritos, oralidade e conhecimentos linguísticos.
} 
eventos de oralidade a que são expostas na sociedade, a partir de atividades relevantes que mostram a importância de dominar as estratégias desse uso da LP.

Muitos problemas relacionados aos aspectos da fala e da escuta no ambiente escolar são atribuídos à "falta de educação" dos estudantes, mas, para além desse olhar pautado no senso comum, o comportamento e as interações orais dos alunos, em sala de aula, passam por questões linguísticas. É necessário que os professores tenham embasamento teórico para ensinar essas questões a seus alunos.

No intuito de fornecer uma contribuição para esse embasamento teórico, apresentaremos, na próxima seção, o conceito de oralidade, conforme Marcuschi (2010), bem como orientações dos PCN (BRASIL, 1997) que fundamentam nossas discussões a respeito do ensino da oralidade. $\mathrm{Na}$ outra seção, discutiremos, de maneira específica, a oralidade nos quadrinhos e apresentaremos alguns recursos para exemplificação. A última seção contém duas propostas de atividades relacionadas ao trabalho com oralidade em sala de aula usando os quadrinhos.

\section{Oralidade em sala de aula}

Consideramos algumas definições imprescindíveis para o desenvolvimento da oralidade em sala e pretendemos, nesta seção, apresentá-las para fundamentar nossa posição a respeito do quão relevante é o desenvolvimento de propostas didáticas envolvendo a oralidade.

Sabemos que há uma crença comum em que a escrita é o lugar do "correto", das "normas", da formalidade e a fala, o lugar do "caos", do "tudo é aceitável". Mesmo que o texto falado tenha um tempo menor de elaboração, ele possui, assim como o texto escrito, uma organização, um caráter estruturado, conforme afirma Jubran (2006). Sob essa mesma perspectiva, Marcuschi (2010) afirma que os textos orais estão em ordem, não são caóticos nem incoerentes ou carentes de coesão interna.

A oralidade que, segundo Marcuschi (2010, p. 25), seria uma prática social interativa para fins comunicativos, que se apresenta sob variadas formas ou gêneros textuais fundados na realidade sonora, é também uma das formas de comunicação que devem ser ensinadas na disciplina de LP, como orientam os PCN. Contudo, há uma escassez nas aulas de LP (e também das outras disciplinas) de atividades que enfatizem o ensino da oralidade. A sala de aula é o ambiente onde deveriam ocorrer interações orais frequentes, objetivando a aquisição, por parte dos alunos, de maneiras eficazes de melhor se expressarem, mas os tópicos discursivos ${ }^{6}$ são, quase sempre, conduzidos pelos professores com pouca (ou nenhuma) intervenção dos estudantes.

A escola deve acolher o aluno com seus conhecimentos adquiridos, sem menosprezá-lo ou diminuí-lo, contudo, tem de oferecer-lhe oportunidades de desenvolver as competências necessárias para utilizar a linguagem oral nos diversos domínios sociais nos quais esse aluno interage. Destacamos a contribuição dos PCN a esse respeito, os quais

\footnotetext{
6 O tópico discursivo pode ser entendido como "aquilo acerca do que se está falando" (BROWN; YULE, 1983, p. 73 apud FÁVERO, 2010, p. 45). "Ele é antes de tudo uma questão de conteúdo, estando na dependência de um processo colaborativo que envolve os participantes do ato interacional" (FÁVERO, 2010, p. 45 , grifo da autora).
} 
preconizam que "eleger a língua oral como conteúdo escolar exige o planejamento da ação pedagógica de forma a garantir, na sala de aula, atividades sistemáticas de fala, escuta e reflexão sobre a língua” (BRASIL, 1997, p. 49).

Consideramos de suma importância que os estudantes tenham acesso às principais categorias que podem ser observadas na análise de um turno conversacional ${ }^{7}$ para que entendam que a oralidade pode e deve ser avaliada e, por isso, deve ser elaborada conforme alguns critérios, tais como: o turno conversacional, os tópicos discursivos, a polidez, a simetria e a assimetria na conversação, o par adjacente, os marcadores discursivos (que são, inclusive, critérios de avaliação do Exame Nacional do Ensino Médio - ENEM). O aluno deve ser preparado para falar e, também, para escutar.

É importante ressaltarmos que, conforme Dolz e Schneuwly (2004), os textos escritos ou orais que produzimos diferenciam-se uns dos outros porque são produzidos em condições diferentes, por isso, faz-se necessário deixar bem claro aos aprendizes qual é o objetivo pretendido com cada atividade e mostrar a eles quais serão os critérios de avaliação. Podemos iniciar um bom trabalho de fala e escuta por meio, por exemplo, de leitura e reconto de um livro literário. Nessa atividade, assim como em outras que envolvam oralidade, o professor pode introduzir conceitos como respeito ao turno, à entonação, à polidez, à postura corporal, ao ritmo, entre outros e, ainda, a percepção de que, assim como a escrita, a fala também é muito importante e segue padrões de formalidade, intenção de comunicação, necessidade de correção, entre outros. Para Monteiro et al. (2013),

a promoção da observação e da análise do uso da língua, em sala de aula, facilitará a tomada de consciência por parte dos alunos de que a fala se constrói no âmbito de práticas dialógicas, aprofundando-se a capacidade de fazer escolhas adequadas às intenções comunicativas e aos interlocutores (MONTEIRO et al., 2013, p. 117).

O trabalho com a oralidade em sala de aula pode ser confundido com a higienização da fala do aluno, quanto à "correção" do "falar errado"; contudo, os PCN já orientam que

Não é papel da escola ensinar o aluno a falar: isso é algo que a criança aprende muito antes da idade escolar. Talvez por isso, a escola não tenha tomado para si a tarefa de ensinar quaisquer usos e formas da língua oral. Quando o fez, foi de maneira inadequada: tentou corrigir a fala "errada" dos alunos - por não ser coincidente com a variedade linguística de prestígio social -, com a esperança de evitar que escrevessem errado (BRASIL, 1997, p. 48-49).

A escola não pode ignorar o fato de que, antes de frequentá-la, o aluno já é falante da língua. Esse fato justifica os diferentes usos da língua no mesmo espaço escolar. Portanto, as situações de ensino também devem contemplar atividades que se valham da compreensão da oralidade, não com o intuito de trabalhar a habilidade de fala, simplesmente, mas que possam subsidiar um bom desempenho dos interlocutores em

\footnotetext{
${ }^{7}$ A ideia de turno relaciona-se às situações em que há alternância entre os membros de um grupo na execução de um determinado evento, alcançando um objetivo comum. Isso também ocorre na conversação, pois "os participantes do diálogo revezam-se nos papéis de falante e ouvinte” (GALEMBECK, 2010, p. 71).
} 
contextos de usos de um gênero textual da vida pública, observando sobre o que falam esses interlocutores e a interação que há entre eles.

Assim, a atitude de correção da "fala errada" do aluno não configura uma contribuição de progresso de trabalhos com a oralidade, pois o que deve ser considerado mais relevante nesse caso, reafirmamos, é a interação.

Concordamos com Fávero, Andrade e Aquino (2014), quando afirmam que a interação exerce uma função tão importante, no texto falado, que poderá orientar ou modificar o desenvolvimento do tópico discursivo. Enumeraremos algumas das categorias que os professores devem ensinar aos alunos, em uma intervenção voltada para a oralidade, entre outros:

- a polidez: entendida como todos os aspectos do discurso que são regidos por regras, cuja função é preservar o caráter harmonioso da relação interpessoal (cumprimentos, "por favor", agradecimentos, entre outros), segundo Kerbrat-Orecchioni (2006);

- a correção: procedimento de reelaboração do discurso que visa a consertar seus "erros", de acordo com Barros (2010);

- os turnos conversacionais: entendidos como a participação de cada interlocutor em uma interação verbal, para Galembeck (1999);

- o tópico conversacional: assunto do qual se está falando, conforme Galembeck (1999);

- a simetria e a assimetria do diálogo: em uma conversação simétrica, os dois falantes interagem por igual na conversação; em uma conversação assimétrica, um falante conduz o tópico conversacional, de acordo, ainda, com Galembeck (1999);

- os marcadores conversacionais: meios de que a língua se serve para facilitar a articulação entre o dito e o contexto, asseguram o desenvolvimento continuado do discurso e operam na organização hierárquica do tópico discursivo (claro, sabe?, certo, né?, acho, então, aí, uhn, ahn, entre outros), de acordo com Fávero, Andrade e Aquino (2014).

$\mathrm{Na}$ elaboração e desenvolvimento de uma proposta didática com a oralidade, o professor deve se embasar em consistentes teorias e definir quais critérios serão avaliados, dado que a oralidade é uma atividade de interação que merece um olhar mais aprofundado. Contudo, as categorias de análise do trabalho com a oralidade não precisam ou devem ser cobradas por meio de metalinguagem, e sim no uso que se faz dessas categorias. Por exemplo, em uma proposta didática utilizando uma História em Quadrinhos (HQ), o professor pode, por meio de perguntas orientadas, levar os alunos a perceberem as marcas de algumas das categorias, tais como estas elencadas por Ramos (2006):

Turno: O que dizem as personagens? De que forma? Qual a função do balão nos quadrinhos? (Se alguém responder que se expressam com a ajuda do balão) As personagens realmente falam? E se não falassem? Por que se expressam um de cada vez? Como nós fazemos: respeitamos a vez do outro? São turnos simétricos ou assimétricos? O que isso indica? Como o aluno faz para se comunicar oralmente? O que há de semelhante e o que existe de diferente? Seria possível contar a mesma história com uma só personagem (importância da interação)? Arriscaria elaborar um roteiro para Maurício de Sousa desenhar? 
Tópico: Sobre o que as personagens falam? Há um assunto central? Resuma em uma palavra. Um só termo conseguiu sintetizar a ideia? Como explicar alguma oposição que possa ocorrer para a depreensão de sentido? Como ocorre no dia a dia: falamos sempre sobre um mesmo assunto? Há casos de mal-entendido, no nosso dia a dia?

Par adjacente: Depois que alguém faz uma pergunta, o que a outra pessoa envolvida no diálogo deve dizer? Ocorre uma resposta propriamente dita na HQ que você tem em mãos (ou outra pessoa responde com outra pergunta)? Isso é possível? Dê exemplos de situações assim. É interessante, dependendo da HQ, apresentar a história quadro por quadro, de modo que o estudante não tenha contato com o desfecho da trama e crie sua própria solução.

Marcador discursivo: é interessante que o aluno se atenha, num primeiro momento, ao código verbal, já que o predomínio é de marcadores não-verbais ou paralinguísticos. Depois, associar ao visual. $\mathrm{O}$ que muda? As expressões - olhares, gestos, fisionomias - mudam de alguma forma o sentido do que foi exposto verbalmente? Ou reforçam? (RAMOS, 2006, p. 7).

Podemos observar que as perguntas orientadas contribuem para a elaboração dos conceitos que vão conduzir a leitura de textos que se valem também de recursos não verbais e, por isso, exigem procedimentos mais específicos, oralmente. É o caso, por exemplo, dos quadrinhos, cujos recursos mais comuns para sua criação e leitura mais produtiva relacionaremos a seguir.

\section{A oralidade e os quadrinhos}

Por muitos anos, as histórias em quadrinhos (HQ) não eram utilizadas como recurso de aprendizagem nos domínios escolares. Segundo Ramos (2014), depois que os documentos oficiais, como a Lei de Diretrizes e Bases da Educação Nacional (LDB), promulgada em 20 de dezembro de 1996, e os PCN orientaram, nos anos seguintes, que existe a necessidade de "linguagens contemporâneas" a serem utilizadas na realidade pedagógica brasileira, surgiram as dúvidas de como utilizar a HQ em sala de aula. No Enem, são comuns questões pautadas em charges, tiras cômicas e cartuns e as bibliotecas públicas escolares de todo o país adquiriram obras em quadrinhos, em 2006, orientadas por uma lista formulada pelo Programa Nacional Biblioteca da Escola (PNBE).

Com as escolas possuindo um acervo de HQ, deve-se saber utilizar este recurso didático riquíssimo para as aulas de LP. A integração de linguagem verbal e linguagem não verbal deve ser lida como um todo, sem desprezar nenhum dos recursos simplesmente para atender a um fim didático e, de acordo com Ramos (2014),

Nem sempre se percebe, mas as histórias em quadrinhos são riquíssimas de recursos de representação da oralidade. Para perceber, basta treinar o olhar [...]. Em quatro quadrinhos, podem-se ler diferentes recursos da língua falada adaptados para a linguagem dos quadrinhos: mudança de tonalidade, uso de balões para indicar fala, trecho dito em voz alta [...]. O uso de elementos da oralidade vai variar de história para história. Mas estarão presentes, em maior ou menor grau. [...] é questão de saber olhar. É difícil esgotar o tema [...]. O pouco, no entanto, já é muito [...] (RAMOS, 2014, p. 79-80). 
É necessário, portanto, que os professores façam uso das diversas possibilidades que as HQs oferecem como recurso para trabalhar a oralidade em suas aulas. Elas são fonte muito rica de representação de recursos da oralidade, sendo difícil esgotar o tema, considerando a diversidade de exemplos que existem. No entanto, com o objetivo de facilitar a identificação de alguns desses recursos dos quadrinhos, apresentamos aqueles que mais comumente são empregados nas tiras. Eles estão relacionados aos valores expressivos da letra e aos recursos gráficos dentro dos turnos. Lembramos que os turnos são representados pelos balões. Para Ramos (2014, p. 81-82), “os balões são o principal recurso dos quadrinhos para representar as falas individuais" e "eles indicam o que a área da Análise da Conversação ${ }^{8}$ chama de turnos conversacionais, nome dado ao que um falante diz durante o processo de interação".

Com relação aos valores expressivos da letra, apresentamos alguns deles, conforme Ramos (2016). Sabemos que os balões apresentam uma letra de forma tradicional, escrita de maneira linear, sem negrito, geralmente em cor preta. Portanto, qualquer corpo de letra diferente desse apresenta resultado expressivamente diferente, engloba outro sentido, por exemplo: i) letra com tamanho menor sugere fala sussurrada ou em tonalidade mais baixa; ii) o negrito pode indicar tom de voz mais alto ou uma fala mais emocional. Para Eguti (2001), o negrito é usado para dar destaque a uma palavra ou expressão. Além de alterações no corpo da letra, Ramos destaca ainda que as palavras escritas sem espaço entre elas sugerem uma fala de forma rápida e que as letras que aparecem duplicadas sugerem prolongamento do fonema.

Apresentamos um exemplo sobre o formato das letras nos quadrinhos com o objetivo de facilitar a leitura. Para isso, comentamos os quadrinhos que compõem a tira, buscando enfatizar ainda mais a leitura.

Figura 1: mínimos detalhes.
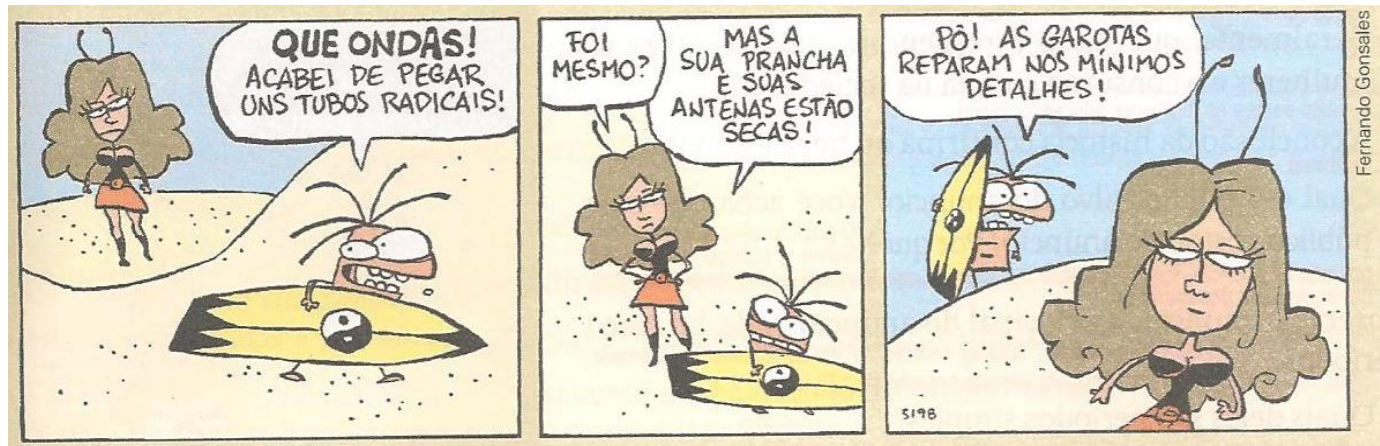

(Fernando Gonsales. Cadê o ratinho do titio. São Paulo: Devir, 2011. p. 14.)

Fonte: CEREJA, W. R.; MAGALHÃES, T. C., 2015, p. 99.

$\mathrm{Na}$ figura 1, já no primeiro quadrinho, a frase "QUE ONDAS!" aparece em tamanho maior e em negrito, também seguida do ponto de exclamação. Num primeiro momento, a leitura poderá ser feita apenas com a entonação de exclamação, observando unicamente a pontuação. No entanto, isso é pouco expressivo. Ao terminar a leitura do terceiro quadrinho, percebemos que toda a sequência narra o fato de que o personagem surfista quer impressionar a garota, evidenciada a qualidade das ondas. Por isso, o negrito e

\footnotetext{
8 "Análise da conversação é uma disciplina que estuda como se organizam as conversas. Trata dos princípios que determinam os diálogos” (LINS, 2014, p. 218).
} 
o tamanho maior sugerem que a frase inicial seja lida com muita expressividade para que a garota sinta no surfista todo o mérito por ter sido capaz de pegar tal onda e, consequentemente, realmente impressioná-la.

Além dos recursos expressivos das letras, há os recursos gráficos dentro dos turnos, dentre os quais o autor destaca as seguintes possibilidades: i) a sucessão de pontos sugere pausa ou hesitação; ii) o balão composto indica que houve um ligeiro silêncio entre uma sequência de fala e outra; iii) a repetição de sílabas ou palavras indicam engasgos, estratégia para reformulação do conteúdo que é dito ou reforço para intensificar alguma emoção; iv) o emprego do hífen separando as sílabas sugere que o personagem falou de maneira silabada; v) o silêncio é representado pela ausência de balões, por balões sem fala, com uso de pontos: o contexto é que indica o real sentido sugerido; vi) quando o personagem estiver falando em excesso, usa-se blá, blá, blá ... ou a onomatopeia bz₹そ; vii) palavrões ou discussões são representados por caracteres desconhecidos ou por signos icônicos; viii) risadas são representadas de maneira semelhante à forma como são emitidas oralmente, variando de autor para autor; ix) para indicar a sobreposição de vozes, parte de um balão aparece sobreposto a outro durante a fala de um personagem; x) o uso de maiúsculas pode indicar a fala em voz bem alta.

Inserimos dois exemplos que buscam ilustrar os recursos acima mencionados.

Figura 2: comida de tubarão.

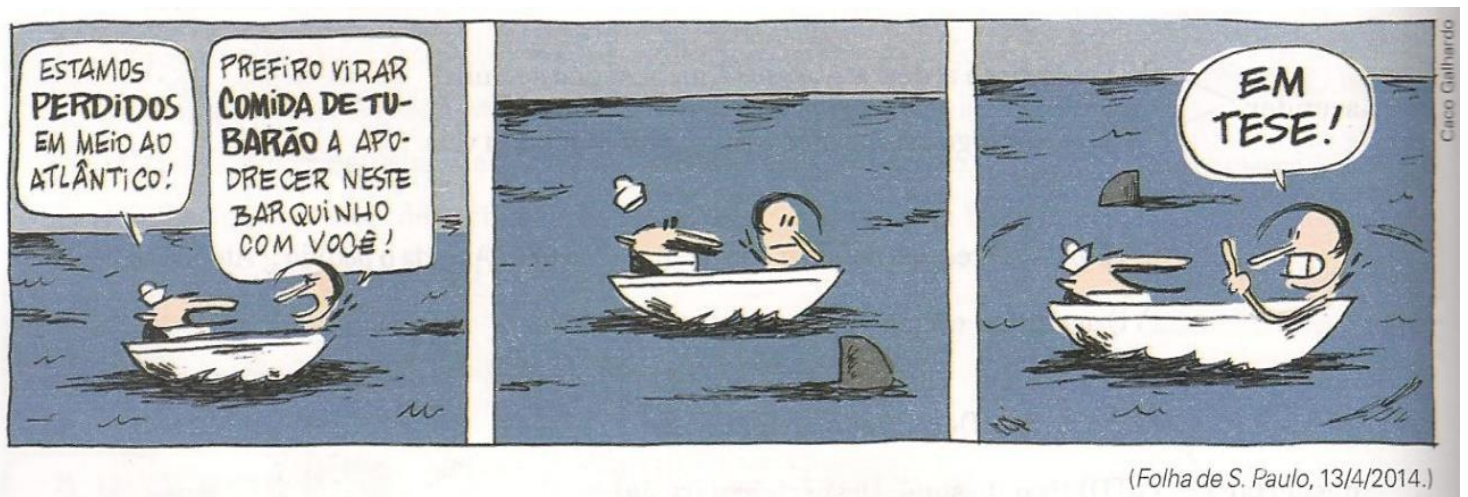

Fonte: CEREJA, W. R.; MAGALHÃES, T. C., 2015, p. 226.

Na figura 2, no segundo quadrinho, temos a ausência de balão, sugerindo o silêncio entre as personagens. É necessário que o leitor faça a leitura da imagem para compreender todo o sentido do silêncio após as falas no primeiro quadrinho, justificando assim a mudança repentina de posicionamento do personagem no último quadrinho. 
Figura 3: o aparecimento da Mula sem cabeça.
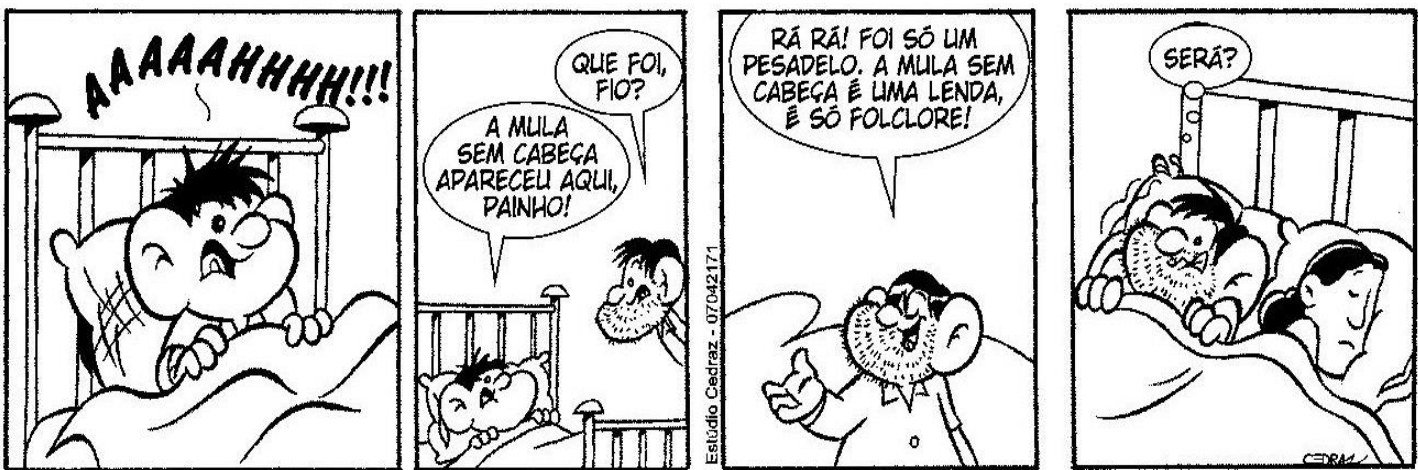

Fonte: CEDRAZ, A. L. R., 2012, p. 43.

No terceiro quadrinho, temos a representação do riso do pai de Zé Pequeno após o filho ter se referido ao aparecimento da mula sem cabeça. Como o riso é representado de diferentes formas, neste caso destacamos "RÁ RÁ!".

Após o apontamento de alguns recursos, apresentamos algumas sugestões de atividades com os quadrinhos, em especial o gênero discursivo tiras, para serem aplicadas a alunos dos anos finais do Ensino Fundamental.

\section{Propostas de atividades com tiras}

As atividades que propomos apresentam como objetivo principal explorar a oralidade em textos que se valem também da linguagem não verbal para evidenciar elementos como a entonação, o ritmo, a postura corporal.

A primeira atividade propõe que os alunos simulem uma situação em que falarão publicamente, exigindo monitoramento da fala, condicionados pelo papel exercido enquanto falante. A segunda atividade visa à leitura de tiras explorando recursos da oralidade nos quadrinhos e seguindo as orientações expostas em cada seção.

\section{Atividade 1}

Transformar o assunto de uma HQ em uma notícia apresentada em uma bancada de jornal.

Para a aplicação da atividade 1, o professor poderá entregar uma cópia da HQ para cada aluno e pedir que se organizem em duplas. Inicialmente cada aluno realizará a leitura da HQ apresentada. O professor conduz a leitura, chamando a atenção dos alunos leitores para questões importantes, como a fisionomia da personagem diante do que vê, as condições ambientais do espaço por que transita, a análise que faz das consequências do progresso urbano e da inconsequente ação do desmatamento, além de chamar a atenção também para a inusitada ação da garota no último quadrinho. No entanto, questionar o sentido que se constrói a partir dessa ação. Caso haja condições, o professor poderá fazer o 
uso do projetor e apresentar os quadrinhos separadamente enquanto conduz a leitura. Esse primeiro momento terá o tempo previsto de uma aula de 50 minutos.

Depois, será produzida uma notícia, informando os fatos dos quadrinhos. Assim, o aluno leitor vai refletir que os quadrinhos, além do humor, apresentam uma crítica social, e irão também exercitar sua habilidade de produtor de texto.

Figura 4: Marina.
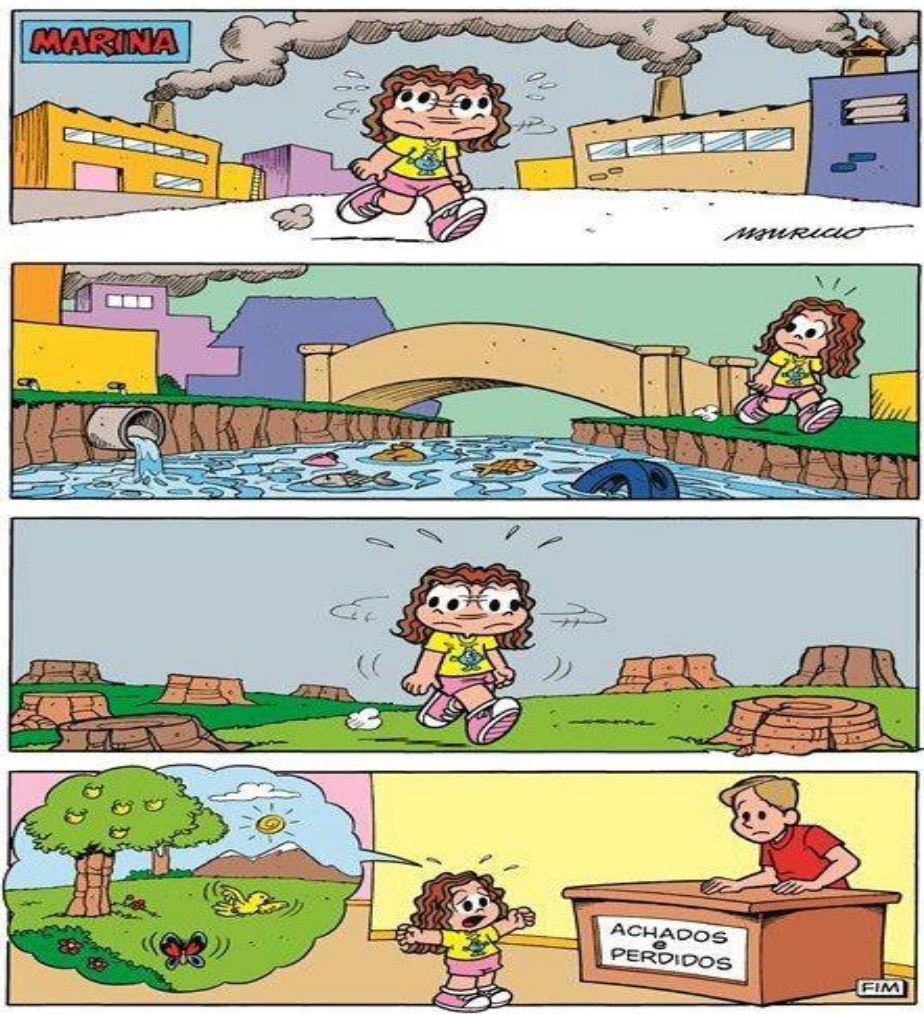

Fonte: $\quad$ <https://jogosdamonica.files.wordpress.com/2015/04/marina-e-o-meio-ambienteperdido.jpg>. Acesso em 17 set. 2018.

Antes de escrever a notícia, o aluno poderá responder às perguntas abaixo, as quais representam os elementos fundamentais para a criação do texto, visando à informação do leitor.

\section{Sugestão de esquema}

Apesar de os quadrinhos de Maurício de Sousa não apresentarem os fatos de uma maneira real, deve-se dizer ao aluno que ele poderá criar os dados como nomes, lugar, data, para que o texto notícia criado cumpra sua função de "informar".

Quando?

Com quem?

Onde?

$>\mathrm{O}$ quê?

$>$ Por quê?

$>$ Como? 
O aluno pode organizar as respostas, observando em que ordem elas podem ser colocadas para que a notícia fique mais bem elaborada. O professor deve lembrá-los também da importância do título (manchete). A leitura da notícia na bancada do jornal poderá ser feita em duplas, com preparação prévia. Esse será o momento em que se evidenciará o trabalho com a oralidade. Propomos que a escrita da notícia e a preparação para apresentação oral se realizem em duas aulas de 50 minutos cada, assim como o tempo previsto para a apresentação também deve ser de uma aula de 50 minutos.

Para a avaliação da atividade, o professor deve observar e comentar com os alunos sobre o respeito ao turno, o tom de voz, o ritmo da leitura, a postura corporal.

Sugerimos também que o professor considere a situação de que

No processo de produção de textos orais, espera-se que o aluno:

- planeje a fala pública usando a linguagem escrita em função das exigências e dos objetivos estabelecidos;

. considere os papéis assumidos pelos participantes, ajustando o texto à variedade linguística adequada;

. saiba utilizar e valorizar o repertório linguístico de sua comunidade na produção de textos;

- monitore seu desempenho oral, levando em conta a intenção comunicativa e a reação dos interlocutores e reformulando o planejamento prévio, quando necessário;

- considere possíveis efeitos de sentido produzidos pela utilização de elementos não-verbais (BRASIL, 1998, p. 51).

Dessa forma, o docente terá melhores condições de analisar se a atividade proposta foi desenvolvida atendendo a objetivos previamente estabelecidos e, principalmente, verificar se os alunos realizaram as atividades orais, demonstrando capacidade de aperfeiçoar o uso que faz da língua, adequando-a às diferentes situações de comunicação.

O professor poderá também aproveitar a atividade para discutir com os alunos sobre o desempenho oral dos colegas e permitir que haja reapresentações a fim de que sejam identificados pontos em que houve progressos ao repensar a mesma atividade.

\section{Atividade 2}

Atividades de leitura de tiras a partir da exploração dos recursos de oralidade dos quadrinhos.

$\mathrm{Na}$ atividade 2, propomos que seja realizada a leitura das tiras, seguindo as orientações em cada uma, explorando recursos de oralidade que os quadrinhos apresentam.

Para a aplicação dessa atividade proposta, sugerimos que o professor divida a turma em pequenos grupos com três ou quatro integrantes e entregue, primeiramente, a cada grupo uma tira diferente da outra. Depois, dê aos grupos um tempo para organizarem a leitura, observando os recursos da oralidade nos quadrinhos presentes em cada uma delas. Enquanto eles se preparam, o professor deve monitorá-los para que a leitura seja de fato bem expressiva, em conformidade com os recursos utilizados. 
Prolongamento na produção sonora da vogal:

Figura 5: o sonho de Zé Pequeno.

XAXADO/Cedraz
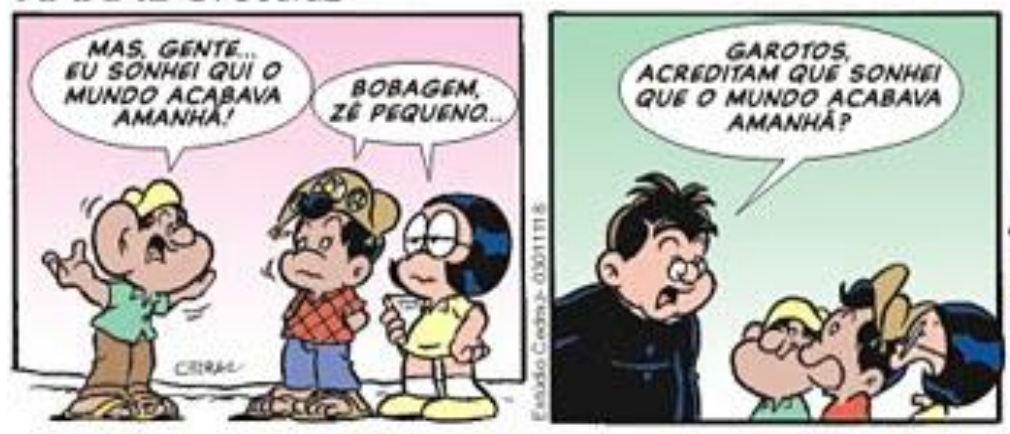

Www.xaxado,com be

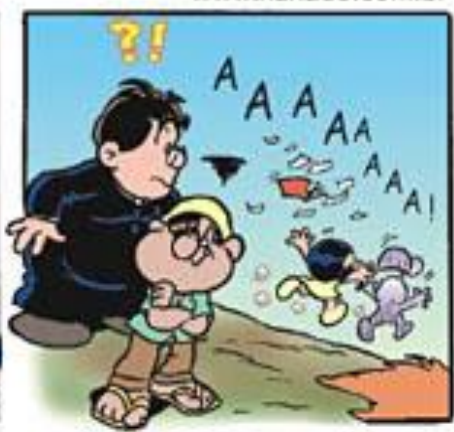

Fonte: <tirasemquadrinhos.blogspot.com.br>. Acesso em: 10 abr. 2016.

No último quadrinho, a disposição do 'A' sugere a ênfase na entonação pelos personagens que correm. $\mathrm{O}$ ' $\mathrm{A}$ ' em negrito e tamanho maior para menor é uma repetição que sugere prolongamento na produção sonora da vogal. É uma ênfase. Mostrar aos alunos o fato de que os personagens vão correndo e se distanciando dos que ficaram, por isso a entonação deve partir do tom mais alto para o mais baixo.

Assalto de turno:

Figura 6: a leitura de Marieta.

XAXADO / Antonio Cedraz
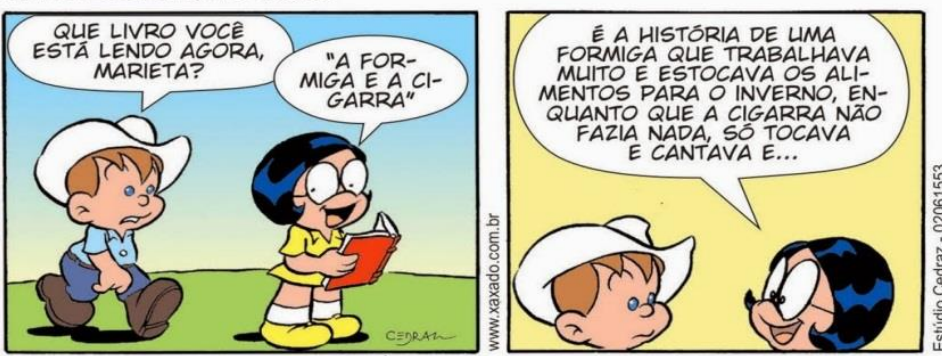

Fonte: <tirasemquadrinhos.blogspot.com.br>. Acesso em: 10 abr. 2016.

Evidenciar o assalto de turno que há do $2^{\circ}$ para $3^{\circ}$ quadrinho. $O$ recurso da pontuação (emprego das reticências) dá ao leitor a impressão de que Marieta continuará a fala no $3^{\circ}$ quadrinho. No entanto, ela foi interrompida na fala por Arturzinho, que se expressa conforme seus interesses financeiros. A frase "JÁ SEI!" denota uma atitude de uma pessoa que não quer mais ouvir, o que quer realmente é falar. Talvez para se impor. A entonação deve procurar mostrar essas situações. 
Fala em excesso:

Figura 7: o boi de Xaxado.
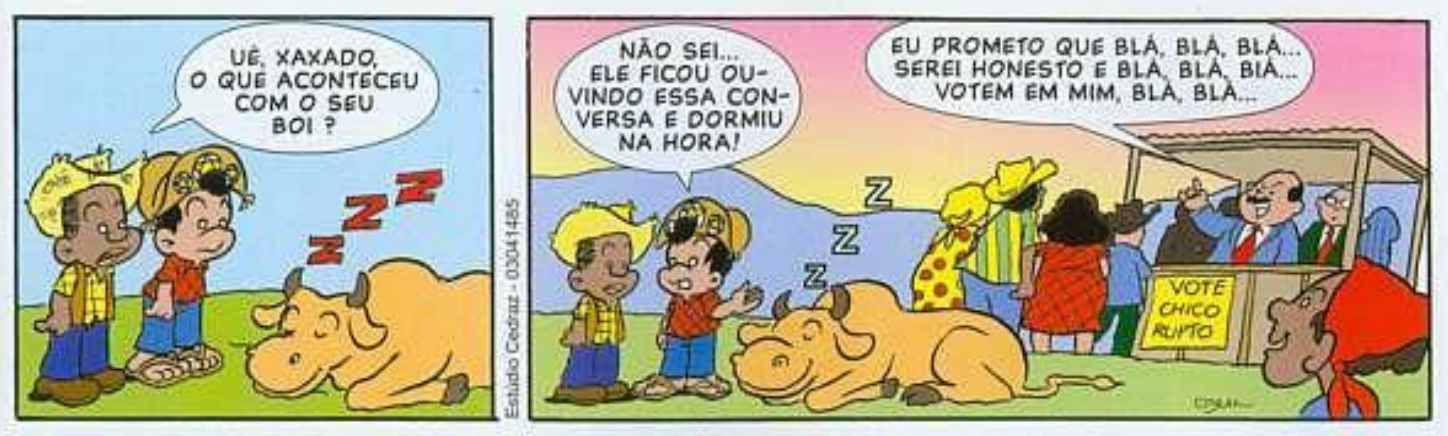

Fonte: <tirasemquadrinhos.blogspot.com.br>. Acesso em: 10 abr. 2016.

O emprego de "blá, blá, blá" mostra a fala em excesso. Podemos pedir aos alunos que leiam separadamente as falas dos personagens e leiam em coro o "blá, blá, blá". Assim, procurar verificar a entonação a ser dada à sequência de "blá, blá, blá..." considerando que além da repetição há o recurso das reticências sugerindo uma fala exaustiva para os ouvintes, e que parece não ter fim.

Negrito e aumento do tamanho da letra:

Figura 8: Zé Pequeno e a máquina de lavar roupas.

XAXADO / Antonio Cedraz
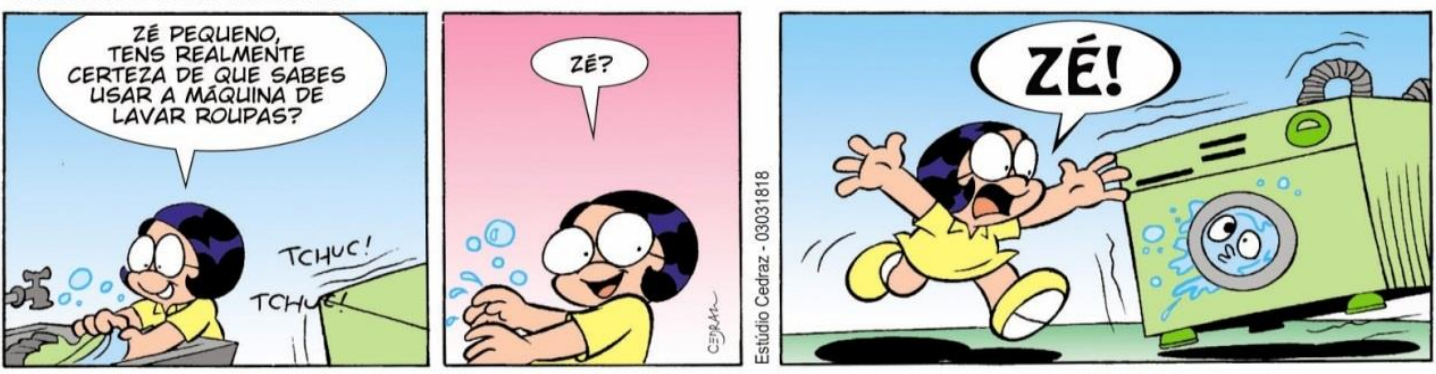

Fonte: <tirasemquadrinhos.blogspot.com.br>. Acesso em: 10 abr. 2016.

Observar as duas formas diferentes para escrita da palavra "ZÉ". Além disso, observar a pontuação. Ler com bastante elevação da vOz o último quadrinho. Falar em voz bem alta.

No segundo quadrinho, há uma situação em que a personagem Marieta simplesmente chama a personagem para confirmar se ela ouviu o que foi dito. A letra está em tamanho e forma normais, sugerindo apenas uma leitura em tom ascendente de voz por apresentar o ponto de interrogação. Já no terceiro quadrinho, devido ao tamanho da letra e o negrito juntamente com o ponto de exclamação, deve ser feita uma leitura de forma a mostrar o desespero da personagem diante do fato inesperado em que se encontra Zé Pequeno, por não ter sabido usar corretamente a máquina de lavar roupas. 
Palavras escritas sem espaçamento:

Figura 9: piadas na sala.

XAXADO / Antonio Cedraz
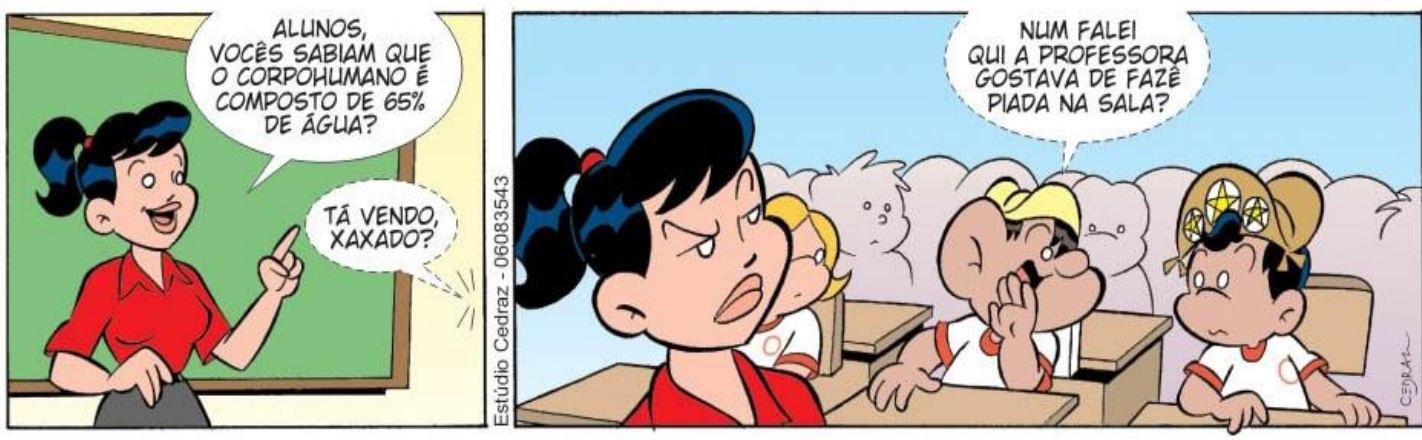

Fonte: <tirasemquadrinhos.blogspot.com.br>. Acesso em: 10 abr. 2016.

Observar que no primeiro balão duas palavras estão escritas sem espaçamento entre elas (CORPOHUMANO), portanto se sugere uma leitura mais rápida. Também há dois balões - as falas de Zé Pequeno - cujas formas indicam o cochicho. Nesse caso, a leitura deverá ser feita com um tom de voz mais baixo, bem próximo mesmo do cochicho.

Letra duplicada:

Figura 10: doação de livros.
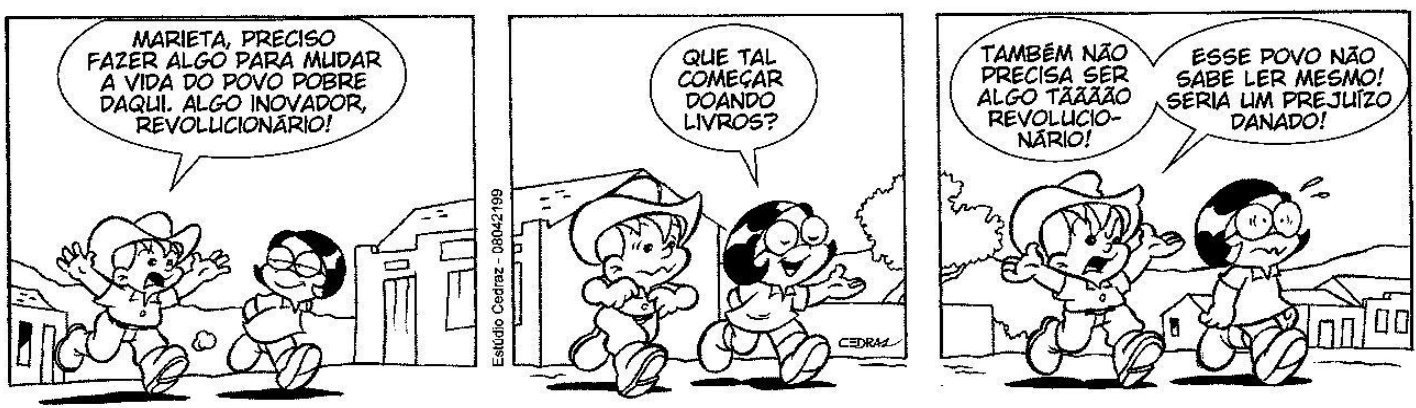

Fonte: CEDRAZ, A. L. R., 2012, p. 48.

No terceiro balão, a fala de Arturzinho aparece com a palavra "TÃ ÃÃ ÃO" com a letra duplicada, sugerindo o prolongamento do fonema na leitura. Portanto a leitura da palavra em destaque deve ser lida assim: prolongando o fonema /ã/. 
Palavras escritas com sílabas separadas:

Figura 11: o mundo de Leiloca.

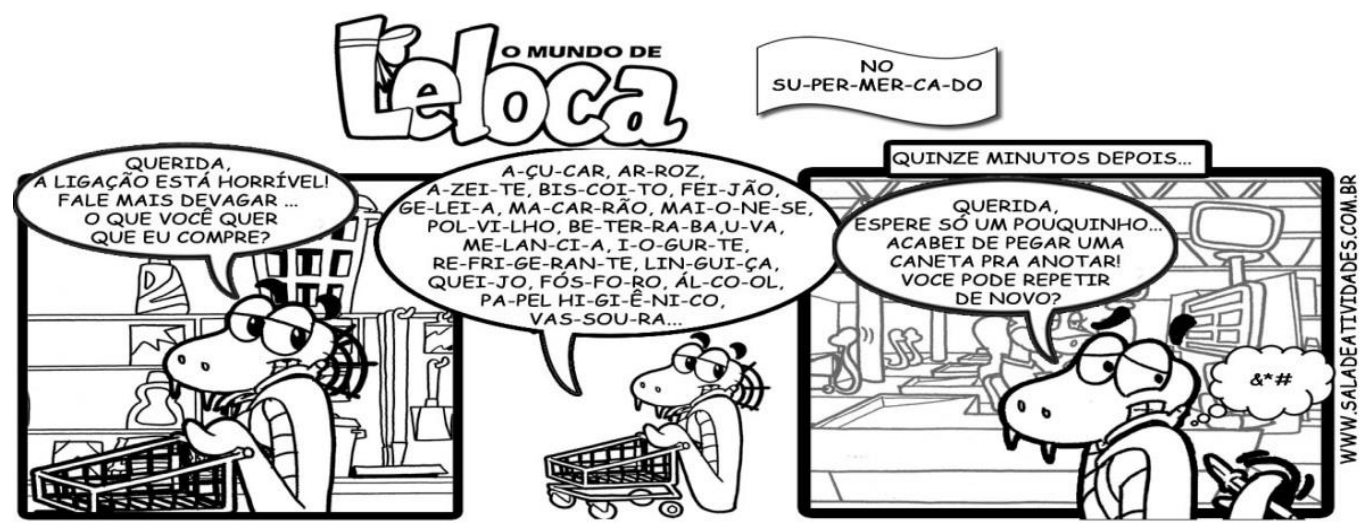

Fonte: $\quad<$ http://www.leloca.com.br/atividades-com-tirinhas-divisao-silabica-supermercado/ $>$. Acesso em: 30 ago. 2017.

Observar o emprego do hífen separando as sílabas das palavras. Isso indica que a personagem falou de maneira silabada. O próprio título já foi escrito de uma forma que nos dá a ideia de uma leitura vagarosa. No primeiro quadrinho, a personagem pede para que quem esteja ao telefone fale devagar. Isso se confirma por meio da legenda no terceiro quadrinho, pois foram gastos quinze minutos para pronunciar vinte e uma palavras. Portanto, deve-se orientar os alunos que leiam as palavras, sílaba por sílaba, e fazendo pausa entre as palavras, justificando o emprego da vírgula.

Ressaltamos que as atividades apresentadas são sugestões para um trabalho com oralidade em sala de aula, fazendo uso dos quadrinhos. Cada professor, ao aplicá-las, deve procurar fazer com que o aluno leitor se aproprie das indicações de leitura que propusemos para que possa ser capaz de atribuir sentido ao texto também por meio de recursos da oralidade.

\section{Considerações finais}

O presente artigo procurou evidenciar a importância de aplicação de atividades que envolvam a oralidade no espaço escolar, enfocando, de uma maneira mais específica, os quadrinhos, em especial, as tiras.

A apresentação dos principais recursos linguísticos característicos da oralidade no gênero discursivo tiras objetivou fundamentar as sugestões de atividades que evidenciam os recursos expressivos da oralidade com esse gênero, para facilitar a sua compreensão. Assim, o leitor pode perceber que o sentido de textos desse gênero se constrói também na habilidade do autor de empregar recursos expressivos da oralidade.

Portanto, as atividades propostas se apresentam como sugestões, podendo os professores aplicá-las como se apresentam ou aprimorá-las. Esperamos que sejam sugestões capazes de contribuir com iniciativas ainda mais promissoras por parte dos professores do Ensino Fundamental no trabalho com oralidade em sala de aula. 


\section{Referências}

BARROS, D. L. P. Procedimentos de reformulação: a correção. In: PRETI, D. (org.). Análise de textos orais. Projetos Paralelos - NURC/SP (Núcleo USP), 1. São Paulo: Humanitas, 2010, p. 147-178.

BRASIL. Ministério da Educação. Parâmetros Curriculares Nacionais (PCN): Língua Portuguesa. Brasília: MEC, 1997.

BRASIL. Parâmetros Curriculares Nacionais (PCN): Língua Portuguesa. Brasília: MEC, 1998.

CEDRAZ, A. L. R. Xaxado: 1000 tiras em quadrinhos. São Paulo: Martin Claret, 2012.

CEDRAZ, A. L. R. A turma do Xaxado. Disponível em: www.tirasemquadrinhos.blogspot.com.br. Acesso em: 10 abr. 2016.

CEREJA, W. R.; MAGALHÃES, T. C. Português: linguagens, $9^{\circ}$ ano. 9 ed. São Paulo: Saraiva, 2015.

DOLZ, J.; SCHNEUWLY, B. Gêneros orais e escritos na escola. São Paulo: Mercado das Letras, 2004.

EGUTI, C. A. A representatividade da oralidade nas histórias em quadrinhos. 2001. Dissertação (Mestrado em Linguística Aplicada) - Universidade de São Paulo, São Paulo, 2001.

FÁVERO, L. L. O tópico discursivo. In: PRETI, D. (org.). Análise de textos orais. Projetos Paralelos - NURC/SP (Núcleo USP), 1, 7 ed. São Paulo: Humanitas, 2010, p. 3963.

FÁVERO, L. L.; ANDRADE, M. L. C. V. O.; AQUINO, Z. Reflexões sobre oralidade e escrita no ensino de Língua Portuguesa. In: ELIAS, V. M. (org.). Ensino de Língua Portuguesa: oralidade, escrita e leitura. São Paulo: Contexto, 2014, p. 13-27.

GALEMBECK, P. T. O turno conversacional. In: PRETI, D. (org.). Análise de textos orais. Projetos Paralelos - NURC/SP (Núcleo USP), 1. 4 ed. São Paulo: Humanitas, 1999, p. 55-79.

GALEMBECK, P. T. O turno conversacional. In: PRETI, D. (org.). Análise de textos orais. Projetos Paralelos - NURC/SP (Núcleo USP), 1. 7 ed. São Paulo: Humanitas, 2010, p. 65-92.

GNERRE, M. Linguagem, escrita e poder. 4 ed. São Paulo: Martins Fontes, 1998.

JUBRAN, C. A. S. Tópico discursivo. In: JUBRAN, C. C. A. S; KOCH, I. G. V.

Gramática do português culto falado no Brasil, v. 1. Construção do texto falado. Campinas: Unicamp, 2006, p. 89-132.

KERBRAT-ORECCHIONI, C. Análise da conversação: princípios e métodos. Trad. Carlos Piovezani Filho. São Paulo: Parábola, 2006. 
LINS, M. P. Lendo o humor nos quadrinhos. In: ELIAS, V. M. (org.). Ensino de Língua Portuguesa: oralidade, escrita, leitura. São Paulo: Contexto, 2014, p. 215-226.

MARCUSCHI, L. A. Produção textual, análise de gêneros e compreensão. São Paulo: Parábola Editorial, 2008.

MARCUSCHI, L. A. Da fala para a escrita: atividades de retextualização. São Paulo: Cortez, 2010.

MONTEIRO, C. et al. Avaliação da competência comunicativa oral no Ensino Básico: um estudo exploratório. Revista Portuguesa de Educação, v. 26, n. 2, p. 111-138, 2013.

RAMOS, P. É possível ensinar oralidade usando histórias em quadrinhos? Revista Intercâmbio, v. XV. São Paulo: LAEL/PUC-SP, p. 1-11, 2006.

RAMOS, P. Recursos de oralidade nos quadrinhos. In: ELIAS, V. M. (org.). Ensino de Língua Portuguesa: oralidade, escrita e leitura. São Paulo: Contexto, 2014, p. 79-101.

RAMOS, P. A leitura dos quadrinhos. 2 ed. São Paulo: Contexto, 2016. 